\title{
Endogenous entry in contests
}

\author{
John Morgan • Henrik Orzen · Martin Sefton
}

Received: 22 July 2008 / Accepted: 20 May 2010 / Published online: 10 June 2010

(C) The Author(s) 2010. This article is published with open access at Springerlink.com

\begin{abstract}
We report the results of laboratory experiments on rent-seeking contests with endogenous participation. Theory predicts that (a) contest entry and rent-seeking expenditures increase with the size of the prize and (b) earnings are equalized between the contest and the outside option. While the directional predictions offered in (a) are supported in the data, the level predictions are not. Prediction (b) is not supported in the data: when the prize is large, contest participants earn more than the outside option. When the prize is small, contest participants earn less. Previous studies of gender and contest competition suggest that females should (a) not perform as well in the contest; and (b) enter at a lower rate. We find some support for (a) but not for (b). Women participate in the contest at the same rate as men.
\end{abstract}

Keywords Contests $\cdot$ Competition $\cdot$ Entry $\cdot$ Experiments

JEL Classification C9 $\cdot$ D4 $\cdot$ D72

We thank Tim Cason, Roman Sheremeta, Dan Kovenock, two anonymous referees and participants at the Centre for Economic Studies/Information und Forschung (CESifo) Venice Summer Institute for very useful comments. Morgan gratefully acknowledges the financial support of the National Science Foundation.

J. Morgan ( $\square)$

Haas School of Business, University of California, Berkeley, USA

e-mail: Morgan@haas.berkeley.edu

H. Orzen

Department of Economics, University of Mannheim, Mannheim, Germany

M. Sefton

School of Economics, University of Nottingham, Nottingham, UK 


\section{Introduction}

Markets owe much of their strength to selection. Individuals choose to participate on the basis of their superior skills, optimistic beliefs, or unique access to resources. "Unfit" agents are outcompeted and ultimately driven from the market. A version of this argument suggests that certain non-optimizing heuristics and biases observed in decision-making experiments are likely to be of little consequence in practice owing to the power of sorting.

A pure expression of the idea of endogenous selection may be seen in market entry experiments. In these games, players can decide to enter, in which case they receive a payoff that is decreasing in the number of entrants, or not enter, in which case they receive a fixed outside option. In the first experimental market entry games, Kahneman (1988) found that the number of entrants was very close to the number predicted by theory. Although subsequent experiments have found slight tendencies toward excess entry when equilibrium predicts few entrants and under-entry when equilibrium predicts many entrants, overall there is remarkable support for equilibrium predictions (see Camerer 2003 for a review).

In real world markets, the payoff to an entrant is obviously not a simple deterministic function of the number of rivals. Rather, competitive processes are shaped by both the number of rivals and, importantly, their post-entry strategies. In other words, payoffs depend crucially on what entrants $d o$, not just on how many there are. However, while numerous laboratory experiments investigate behavior under various forms of competition, these studies typically confine attention to the case where the number of players is exogenous.

In this paper we report experiments where entry is endogenous and where entrants subsequently engage in competition, and ask how well the outcomes are captured by equilibrium theory. We distinguish between behavior - the choices made by playersand payoffs - the resulting earnings. While behavior might differ from equilibrium predictions, market forces exert strong pressure on earnings. In our experiments, players choose between entering a contest and accepting a fixed outside option. Contest entrants play a version of Tullock $(1967,1980)$ rent-seeking game. ${ }^{1}$

Previous experiments on rent-seeking games, summarized in Sect. 2, exhibit substantial discrepancies between actual investment levels and equilibrium predictions. Indeed, the broad conclusion in this literature is that standard equilibrium analysis does a poor job in describing behavior. As a result, actual payoffs differ widely from equilibrium payoffs. Can endogenous entry—the discipline of the market-restore equilibrium outcomes?

In Sect. 3 we describe theoretical properties of our endogenous entry game. Endogenizing participation provides an additional mechanism for bringing payoffs in line with equilibrium predictions - the force of entry. First, even if players overinvest in the contest, this over-investment will be anticipated and "priced" into the entry decision. Profitable contests should attract more contestants and unprofitable contests should shed contestants, up to a point where the payoffs from opting into

\footnotetext{
1 See Skaperdas (1996) for axiomatic foundations of this specification.
} 
the contest and opting out are approximately equal. Second, players with a tendency to over-invest receive feedback in the form of lower returns relative to the safe outside option. With experience, these individuals will learn to avoid the "temptation" to over-invest by staying out of the contest in the first place, so that selection may align contest behavior and contest profits back with equilibrium predictions.

Section 4 describes our experiments. Key features that distinguish these from previous experiments are: (i) entry into the contest is endogenous and (ii) the game is repeated fifty times. At the end of each round, all players - entrants and non-entrants learn about contest expenditures and outcomes as well as how much entrants and non-entrants earn. These features give players opportunities to learn how the number of contestants and contest strategies affect contest payoff, and also give players opportunities to react to over- or under-investment by exit/entry decisions.

Section 5 describes our results. When a small contest prize is offered, there is initially too much entry and investment relative to equilibrium predictions. Over time, both entry and investment are reduced but remain above equilibrium levels. As a result, subjects choosing to participate in the contest earn about $5 \%$ less on average and at greater risk than if they had chosen the outside option. When a large contest prize is offered, there is initially too little entry and too much investment compared to equilibrium predictions. Investment gets close to equilibrium levels over time but entry is consistently too low. As a result, subjects opting for the contest earn about $10 \%$ more than those opting for the outside option.

We also examine the relationship between gender, decisions to enter contests, and contest strategies. Consistent with the previous literature, women, on average, obtain lower earnings in the contest than men. With respect to entry, our findings diverge from the earlier literature. Despite their lower earnings, women opt into the contest at roughly the same rate as men.

Concluding comments, including some suggestions for further research are offered in Sect. 6.

\section{Previous experiments}

Several experiments have studied rent-seeking contests with exogenous numbers of participants. In strictly one-shot games, Anderson and Stafford (2003) find substantial overdissipation. With two players rent-seeking expenditures are almost twice the predicted level, and for more than two players they find that total expenditures exceed the prize. In contrast, Schmidt et al. (2006) find that with four players expenditures are $30 \%$ below predicted levels.

One might expect that discrepancies between actual and predicted expenditures would be eliminated by experience. However, even in experiments where subjects play repeatedly substantial discrepancies remain after many periods. Shupp (2004) introduces repetition into the Schmidt et al. design and finds some tendency for rentseeking to increase over time, but, averaging over all periods, rent-dissipation is still around 30\% lower than predicted. In two-player contests with thirty periods, Potters et al. (1998) as well as Fonseca (2009) find rent-seeking expenditures of 68 and 100\% above equilibrium respectively. 
Table 1 summarizes results from experiments with symmetric contests where a contestant's probability of winning an exogenous prize is equal to her expenditure as a fraction of total expenditure. We normalize the parameters so that each study can be represented by the expected earnings function $w+x_{i} P / X-x_{i}$, where $w$ is the endowment (and maximum permissible individual investment), $x_{i} \in\{0,1, \ldots, w\}$ is the individual investment, $X$ is the group investment, and $P$ is the prize. The last column shows rent-seeking expenditures as a percentage of those predicted by equilibrium (assuming risk neutrality).

The diversity of findings is remarkable. One aspect that distinguishes the two studies finding under-dissipation from the others is that endowments were smaller than the prize amount. As a consequence, equilibrium predicts that participants will place a substantial fraction of their endowment (about two-thirds) at risk in the contest. In contrast, studies finding overdissipation suggest that subjects will risk one-third of their endowment or less in equilibrium. However, given the large number of design differences across studies, one should be cautious in attributing differences to one variable. The main lesson conveyed in Table 1 is that when an exogenous number of players compete in a contest, equilibrium predictions fare poorly.

How might introducing an outside option affect these results? Endogenous entry provides a degree of market discipline. In previous contest experiments with an exogenous set of players anomalous investment decisions can only be eliminated to the extent that participants learn from experience to make sensible adjustments to their expenditures. With endogenous entry an additional force may operate whereby participants who are less successful opt-out of the contest while those who are more successful opt-in, and this selection effect may result in investment decisions being more closely aligned with equilibrium predictions.

Previous experiments have found that the introduction of market forces can play an important disciplining role in reducing or even eliminating discrepancies between observed behavior and theory. Braga et al. (2009) provide a useful overview of experiments studying willingness to pay/willingness to accept disparities and preference reversal phenomena. They also provide important results on how competitive dynamics influence behavior, noting that while some market mechanisms eliminate preference reversal anomalies, others do not (see also Cox and Grether 1996). They conclude that it is not market experience per se that drives out anomalies, but rather more nuanced features of the competitive forces. As far as we are aware, the only previous study of a Tullock contest preceded by an entry decision is one of Anderson and Stafford's treatments. They find that entry is reduced by introducing an entry fee, but even with the fee, rent-seeking expenditures exceed predicted levels. The one-shot nature of their experiment may, however, limit the effectiveness of entry fees as a disciplining device.

\section{Contests with endogenous participation}

Consider the following simple contest with endogenous participation. $N$ risk-neutral individuals can enter a rent-seeking contest or choose an outside option worth $F$. Each individual has a fixed endowment worth $w$. Individuals endogenously choose the time, $t$, at which to make the decision to opt-in or opt-out. Time is continuous in 


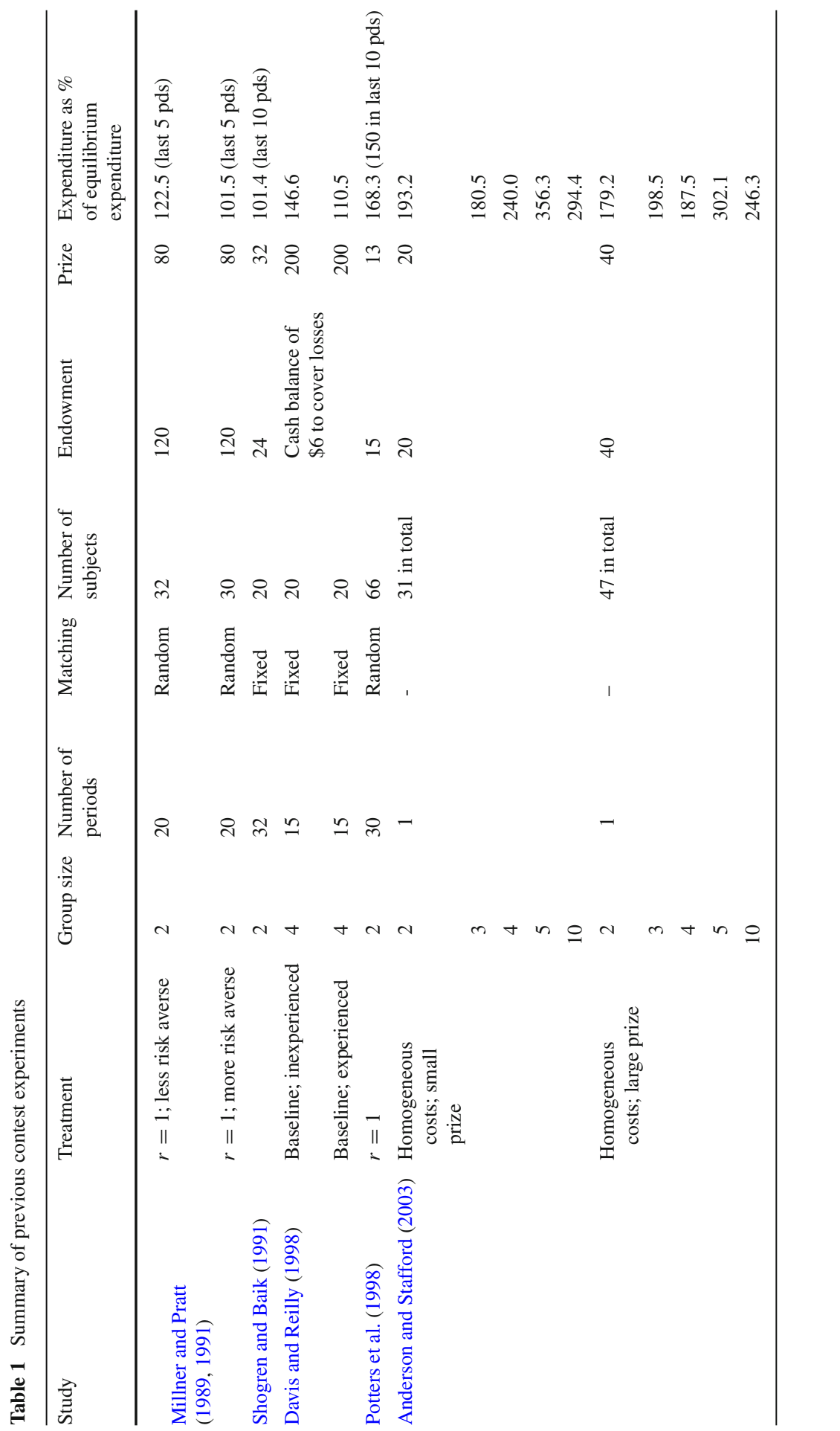




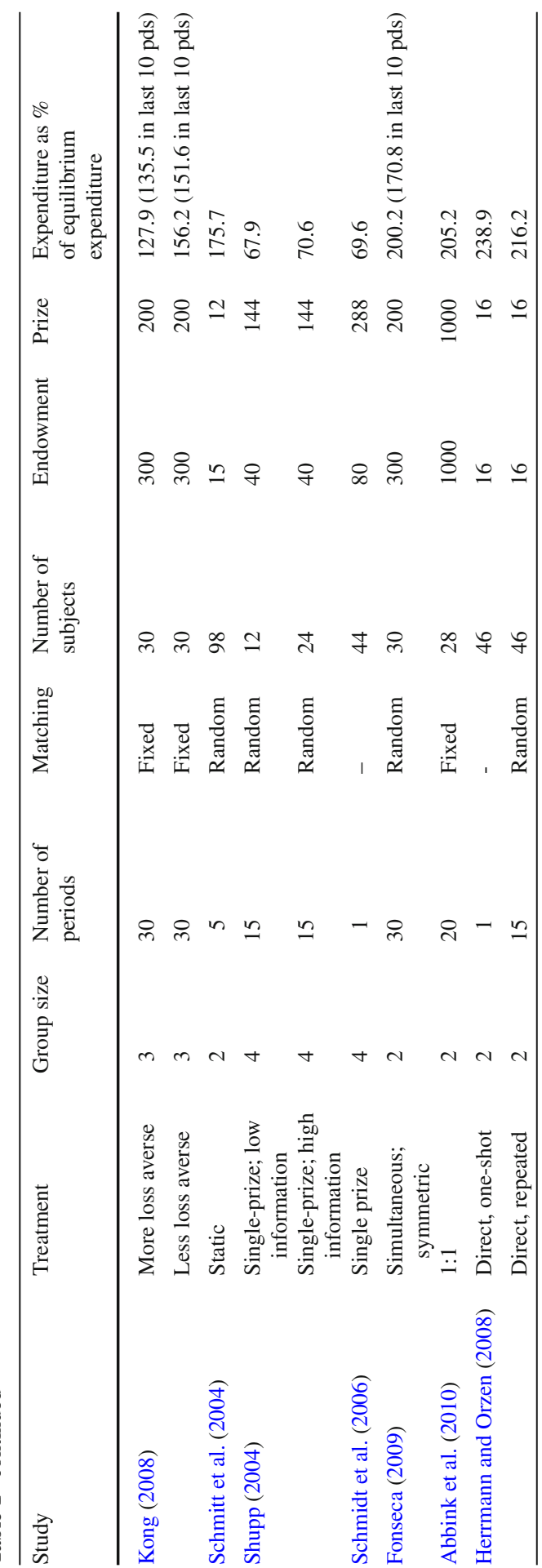


the model starting at time $t=0$ and ending at time $t=1$, at which point the contest takes place. All decisions are publicly observable at the instant they are made. Once an individual has made the decision to opt-in or out, he or she cannot subsequently reverse that decision. If an individual has not made a decision at time $t=1$, a decision is selected for him or her-equally likely to be an opt-in or opt-out. The number of contest participants at each point in time is common knowledge. Individuals opting into the contest simultaneously make investment decisions $x_{i} \in[0, w]$. Aggregate investment is denoted by $X=\sum_{j} x_{j}$ where the summation is taken over all contestants. The probability that player $i$ wins the contest is given by the contest success function $x_{i} / X$.

Earnings are determined as follows: If a player opted out of the contest, then she earns $w+F$. If she opted in and won the contest, she earns $w+P-x_{i}$ where $P$ is the value of the prize for winning the contest. If she opted in and lost the contest, she earns $w-x_{i}$. The contest has only a single winner; thus, the expected earnings of a contestant who invests $x_{i}$ when total investment by all contestants is $X$ is given by $\pi_{i}=w+x_{i} P / X-x_{i}$.

\subsection{Equilibrium}

Suppose that $n$ agents have entered the contest. The unique symmetric Nash equilibrium entails investments equal to $x_{n}^{*}=(n-1) P / n^{2}$ yielding an equilibrium expected payoff of $\pi_{n}^{*}=w+P / n^{2}$ to everyone who opted into the contest. Clearly, payoffs decrease with the number of individuals entering the contest.

It remains to identify the number of individuals participating in the contest. We assume that $P>F>P / N^{2}$, so that there is an incentive for at least one player to enter the contest, but the outside option is more attractive than a contest involving all players. We also focus on generic parameter values where $\sqrt{P / F}$ is not integer valued. This implies that in any pure strategy equilibrium, the equilibrium number of participants, $n^{*}$, occurs when one additional entrant would reduce the expected payoff from the contest below that of the outside option. That is, in equilibrium, $n^{*}$ is the largest integer such that $P / n^{* 2}>F$. For generic parameter values opting into the contest, in equilibrium, yields strictly higher expected payoffs than opting out. This suggests that

$$
n^{*}=\lfloor\sqrt{P / F}\rfloor
$$

participants will opt into the contest (where $\lfloor$.$\rfloor denotes the integer floor function)$ and subsequently play the unique symmetric equilibrium of the rent-seeking game. Of course, since all of the players are identical in the model, the identity of the players choosing to opt into the contest is not uniquely determined. We can, however, determine the timing of entry decisions. As Proposition 1 below shows, all entry occurs at time close to $t=0$.

To formally arrive at this conclusion, we slightly amend the model. Assume that when the clock starts, each player is subject to a private random delay time, $d_{i}$, after 
which entry is possible. The realization $d_{i}$ is drawn from a CDF $F$ having support on $[0, \varepsilon]$ with positive density everywhere, where $\varepsilon<1$. The introduction of this delay parameter serves to avoid the consideration of events where individuals make choices at exactly the same time. Thus, contestant $i$ is free to enter at any time $t$ contained in the interval $\left[d_{i}, 1\right]$. Without loss of generality, order the indices of the contestants such that $d_{1}<d_{2}<\cdots<d_{N}$.

Proposition 1 Given the continuation payoffs from above, in the unique perfect Bayesian equilibrium (PBE), contestants $i=1,2, \ldots, n^{*}$ enter the contest at time $d_{i}$. All others remain out of the contest.

Proof Given the prescribed strategy, no player can profitably deviate. Players with indices $i \leq n^{*}$ enjoy strictly higher payoffs by entering than not while the reverse is true for players with indices $i>n^{*}$.

It remains to show that no strategy involving additional delay comprises a PBE. To establish this claim, it is useful to derive some structural properties of any PBE.

1. In any PBE, players only enter if the current number of entrants is $n^{*}-1$ orfewer. Since the continuation payoffs from additional entry when there are already $n^{*}$ or more entrants are lower than the outside option, staying out of the contest is more profitable.

2. In any PBE, exactly $n^{*}$ players enter.

If fewer than $n^{*}$ players enter, a contestant scheduled not to enter can profitably deviate by entering. Property 1 rules out the case where more than $n^{*}$ contestants enter.

3. In any PBE, only players with indices $i \leq n^{*}$ choose to enter.

Suppose not. Then an entrant with index $i \leq n^{*}$ chooses not to enter while one with index $j>n^{*}$ enters. However, contestant $i$ can profitably deviate by entering at time $d_{i}$ and, since $j$ is informed about this entry, he will optimally choose not to enter.

With these properties in hand, the only other possibility for a PBE is one where players enter at time $d_{i}+\tau$ if there are $n^{*}-1$ or fewer current entrants and stay out otherwise, where $\tau>0$ is a commonly known constant. Under such a putative equilibrium, a player with index $j>n^{*}$ can profitably deviate by entering at time $d_{j}$ if there are $n^{*}-1$ or fewer current entrants. Thus, in any PBE, all entry occurs at the earliest possible moment.

This simple model of contests with endogenous entry is a straightforward extension of the classic Tullock rent-seeking model with the addition of what is, in effect, a zero profit condition. Essentially, the model is a slightly modified version of that analyzed in Corcoran (1984) as well as Corcoran and Karels (1985). Somewhat related is Fullerton and McAfee (1999), who study contests where agents are heterogeneous and entry is determined by an auction. Mathews and Namoro (2008) consider entry decisions when each agent faces multiple possible contests. See Nitzan (1994) and Konrad (2007) for excellent surveys of the theoretical rent-seeking literature. 


\subsection{Further considerations}

The preceding analysis assumes that all contestants maximize their own expected earnings. Of course, if contestants have different motivations or are boundedly rational then contest expenditures might exceed or fall short of equilibrium levels. We show that endogenous entry into contests may nevertheless bring earnings into line with standard predictions.

For example, suppose agents are not attempting to earn as much as possible for themselves, but rather are attempting to beat other contestants. More specifically suppose a contestant maximizes the difference between her earnings and the average earnings of other contestants, i.e. her objective is $u_{i}=\pi_{i}-\sum_{j \neq i} \pi_{j} /(n-1)$. Then it can be shown that equilibrium of the $n$-player game with payoffs $\left(u_{1}, \ldots, u_{n}\right)$ involves full dissipation. Thus, relative earnings considerations may make contestants even more competitive than is predicted by equilibrium analysis applied to absolute earnings. ${ }^{2}$

How does adding an outside option and endogenizing participation in the contest alter this conclusion? If we apply maximization of earnings differences to the $N$-player game, taking into consideration payoffs of $n$ contestants and $N-n$ outsiders, then in the contest stage each contestant spends

$$
x=\frac{N}{N-1} \frac{n-1}{n^{2}} \quad P=\frac{N}{N-1} x_{n}^{*} .
$$

Expenditures exceed the equilibrium level described in the previous sub-section, but already, because contestants compare their earnings with outsiders as well as other contestants, expenditures fall short of full dissipation. The expenditures lead to expected contest earnings of

$$
\pi=w+\frac{N-n}{N-1} \frac{P}{n^{2}}
$$

while outsiders earn $w+F$. Earnings differences are given by

$$
u_{c}(n)=\frac{N-n}{N-1}\left(\frac{N-n}{N-1} \frac{P}{n^{2}}-F\right)
$$

for a contestant and

$$
u_{o}(n)=\frac{n}{N-1}\left(F-\frac{N-n}{N-1} \frac{P}{n^{2}}\right)
$$

\footnotetext{
2 This is closely related to predictions of over-dissipation relative to Nash equilibrium made by evolutionary models. Noting that a contestant's expected earnings can be written as $\pi_{i}=w+x_{i}(P-X) / X$, it should be clear that for any profile of expenditures, as long as there is incomplete dissipation, $P>X$, the most successful contestant will be the one who spends the most. Thus, evolutionary or imitative processes, whereby better performing strategies receive more reinforcement, lead to over-dissipation relative to equilibrium. Hehenkamp et al. (2004) show that for a contest with $n$ players the Nash equilibrium strategy is not evolutionary stable, and the unique evolutionary stable strategy involves full dissipation: $x=P / n$. Morgan et al. (2003) show that maximization of relative payoffs generates similar excessive competitiveness in auctions.
} 
for an outsider. Thus, the subgame perfect equilibrium of the game where players maximize earnings differences has $n$ players enter where $n$ must satisfy $u_{o}(n) \geq u_{c}(n+1)$, which ensures that an outsider cannot increase her payoff by entering, and $u_{c}(n) \geq$ $u_{o}(n-1)$, which ensures that the last contestant to enter did not decrease her payoff. Although for any $n$ contestants still spend more than $x_{n}^{*}$, the entry decisions result in fewer entrants, so the expected earnings in the contest equal the value of the outside option (modulo integer constraints on participation).

In summary although alternative preference formulations affect investment levels in contests with a fixed number of entrants, earnings equalization is a stronger result that holds across a broader class of models than the standard equilibrium model of Sect. $3 \cdot 1 .^{3}$

\section{Experimental design and procedures}

The experiment consisted of six sessions conducted at the University of Nottingham in Spring 2008. A total of 102 subjects, recruited from a campus-wide distribution list of undergraduates, participated in the experiment, and no subject appeared in more than one session. Of these subjects 54 (33 female and 21 male) participated in three sessions using our small prize treatment and 48 (19 female and 29 male) participated in three sessions using our large prize treatment.

A session consisted of either 12 or 18 subjects, and the following procedures were common to all sessions. At the beginning of a session, the subjects were seated at computer terminals and given a set of instructions which were read aloud. Any questions were dealt with in private by a monitor. No communication between subjects was permitted, and all choices and information were transmitted via computer terminals. Before the decision-making part of the experiment began, groups of six subjects were randomly formed and these remained fixed for the entire session. Subjects did not know which of the other people in the room were in their group. This design resulted in nine independent groups for the small prize treatment and eight independent groups for the large prize treatment.

The decision-making part of the session then consisted of fifty rounds. In each round, a subject was given 100 points and had to choose between two options, labeled "A" and "B". A timer was displayed on the subjects' screens, counting down $15 \mathrm{~s}$. Subjects were informed that if they did not make a choice within the time limit the computer would make a choice for them at random. ${ }^{4}$ During this time they could see

\footnotetext{
3 Unequal expected earnings would arise in equilibrium if players are risk averse or get utility from participating in or winning the contest. The effect of risk aversion on investment levels is ambiguous, but in equilibrium expected earnings from the contest would have to exceed the outside option in order to compensate participants for risk. Similarly, if players get utility from participating in or winning the contest the effect on investment levels is ambiguous, but in equilibrium expected earnings from the contest will fall short of the outside option. Sheremeta (2010) finds that subjects expend real effort to win a prize of zero value illustrating the utility some individuals receive simply from winning.

4 Once the timer on the display had counted down from 15 , the computer made the decision only after ' 0 ' had been displayed for one second. Thus, the effective time limit for subjects was, in fact, 16 ss. About 3\% of decisions were made by the computer. Our results are unaffected by the inclusion or exclusion of this data.
} 
Table 2 Experimental design and equilibrium benchmarks

\begin{tabular}{|c|c|c|c|c|c|c|c|c|c|c|c|}
\hline \multirow[t]{3}{*}{ Treatment } & \multicolumn{4}{|l|}{ Parameters } & \multicolumn{7}{|c|}{ Equilibrium predictions } \\
\hline & \multirow{2}{*}{$\begin{array}{l}\text { Endowment } \\
(w)\end{array}$} & \multirow{2}{*}{$\begin{array}{l}\text { Players } \\
(N)\end{array}$} & \multirow{2}{*}{$\begin{array}{l}\text { Outside pay } \\
(F)\end{array}$} & \multirow{2}{*}{$\begin{array}{l}\text { Prize } \\
(P)\end{array}$} & \multicolumn{6}{|c|}{ Individual investment ${ }^{\mathrm{a}}$} & \multirow{2}{*}{$\begin{array}{l}\text { Entrants } \\
\left(n^{*}\right)\end{array}$} \\
\hline & & & & & 1 & 2 & 3 & 4 & 5 & 6 & \\
\hline Small prize & 100 & 6 & 10 & 50 & 0.0 & 12.5 & 11.1 & 9.4 & 8.0 & 6.9 & 2 \\
\hline Large prize & 100 & 6 & 10 & 200 & 0.0 & 50.0 & 44.4 & 37.5 & 32.0 & 27.8 & 4 \\
\hline
\end{tabular}

${ }^{\text {a }}$ Conditional on number of entrants $\left(x_{n}^{*}\right)$

how many members of their group had chosen A, how many had chosen B, and how many had not yet chosen. This information was anonymous, in the sense that subjects could only see the number in each category and could not track who of the other group members were in each category from round to round. We incorporated this design choice to minimize the ability of subjects to build reputations. ${ }^{5}$

Those choosing option A received an additional 10 points for the round, while those choosing option B competed for a prize. The prize varied across sessions according to treatment: in the small prize treatment the prize was worth an additional 50 points, while in the large prize treatment it was worth an additional 200 points.

In both treatments, if only one person entered a contest, that person received the prize and no contest was conducted. Otherwise, subjects choosing to compete for a prize could buy up to 100 'contest tokens' at a cost of 1 point per token. These choices were made independently and simultaneously. Each contestant then received the prize with a probability equal to the number of tokens he or she bought divided by the total number of tokens bought by all contestants in his or her group. The winner was determined using a computerized lottery wheel. All subjects in the group, whether they had entered or not, observed the purchase decisions and the lottery for the contest option. Again, this information was anonymous in the sense that subjects could see the purchase decisions but they could not associate them with specific group members. All subjects were also reminded of the fixed payment from the outside option. Table 2 summarizes the experimental treatments and provides the relevant equilibrium predictions for our parameters.

At the end of the session, one round was chosen at random and subjects were paid in cash according to their point earnings from this selected round. An exchange rate of $£ 0.10$ per point was applied. Sessions took around $75 \mathrm{~min}$ and earnings ranged between zero and $£ 29.60$, averaging $£ 11.11$ (approximately US\$22 at the time of the experiment).

\section{Results}

In Sect. 5.1, we focus on rent-seeking expenditures in the contest. Section 5.2 takes up the question of entry into the contest and the implications for expected payoffs

\footnotetext{
5 In many experiments subjects are given an ID and information screens associate decisions with IDs. In an experiment such as ours this would allow subjects to establish reputations, and so we did not use IDs at all.
} 


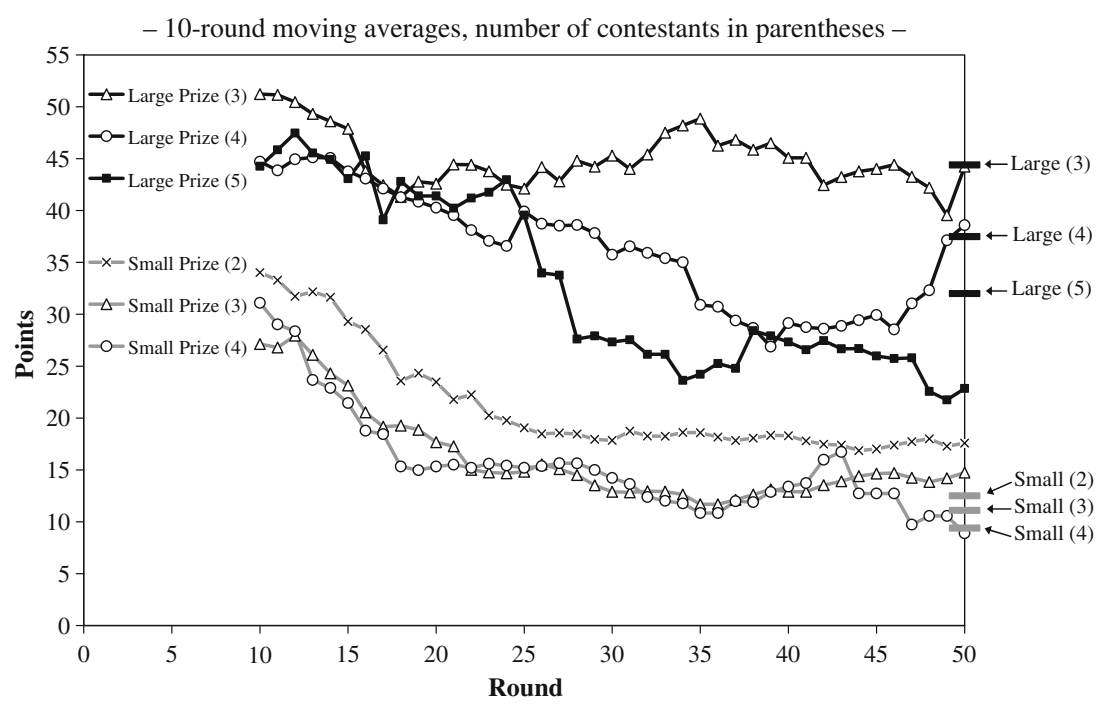

Fig. 1 Rent-seeking expenditures per contestant (in points) over time

from entering versus not entering. Finally, Sect. 5.3 examines how gender correlates with subject choices. In particular, our experiment shares many of the same features as recent influential studies on the relationship between gender and competition enabling meaningful comparisons.

\subsection{Rent-seeking expenditures}

Figure 1 illustrates contest expenditures over time, conditional on the treatment (small prize vs. large prize) and conditional on the number of entrants. The figure only presents the time series for subgames with sufficient number of observations: In the small prize treatment, contests with five or six contestants were rarely observed and are not shown here; in the large prize treatment, contests with two or six contestants were rarely observed and are not shown here. Overall, the figure accounts for $96 \%$ of all investment decisions recorded. The relevant theoretical benchmarks from Table 2 are displayed on the right-hand side as horizontal blocks.

As the figure shows, subjects adjust their investing behavior over time. In the early rounds of the small prize treatment we observe very substantial excess expenditures relative to the theoretical predictions. Average expenditures in the first 10 rounds in Small Prize (2), (3) and (4) exceed the corresponding equilibrium benchmarks by 172,145 and $231 \%$, respectively. Overly aggressive investing is also present in the early rounds of the large prize treatment, but less pronounced: The analogous figures for Large Prize (3), (4) and (5) are 15, 19 and 38\%, respectively. With experience, subjects learn to moderate their investment choices. Although over-investment is still present-expenditures in the last 10 rounds of Small Prize (2) and (3) exceed the equilibrium benchmark by 41 and $33 \%$-it is less extreme than in the early rounds. 
Table 3 Determinants of individual contest investment

\begin{tabular}{llllll}
\hline & Small prize & & & \multicolumn{2}{l}{ Large prize } \\
\cline { 2 - 3 } \cline { 6 - 6 } \cline { 5 - 6 } & All rounds & Rounds 26-50 & & All rounds & Rounds 26-50 \\
\hline Constant & $29.583^{* * *}(4.767)$ & $16.094^{* * *}(6.086)$ & & $86.912^{* * *}(14.757)$ & $86.176^{* * *}(25.898)$ \\
Number of Entrants & $-2.098^{*}(1.242)$ & $-2.613(1.811)$ & & $-10.144^{* * *}(3.384)$ & $-12.588^{* *}(4.957)$ \\
Round & $-0.339^{* * *}(0.113)$ & $0.072(0.059)$ & & $-0.292^{* *}(0.144)$ & $-0.021(0.122)$ \\
Female & $6.091^{*}(3.309)$ & $5.522^{* *}(2.316)$ & & $0.279(5.255)$ & $-0.170(5.701)$ \\
$\begin{array}{l}\text { Number of } \\
\quad \text { observations }\end{array}$ & 1143 & 544 & & 1438 & 719 \\
Wald $\chi^{2}(3)$ & $13.88^{* * *}$ & $9.87^{* *}$ & $30.00^{* * *}$ & $7.01^{*}$ \\
\hline
\end{tabular}

Tobit analysis with robust standard errors in parentheses

* Significant at $10 \%,{ }^{* *}$ significant at $5 \%,{ }^{* *}$ significant at $1 \%$

Moreover, in Small Prize (4), Large Prize (3) and Large Prize (4), investments are close to predictions - the averages over the last 10 rounds deviate by $-5 \%, \pm 0 \%$ and $+3 \%$, respectively - and in Large Prize (5) average investments are now even $29 \%$ below the equilibrium level. ${ }^{6}$

For a more formal analysis we examined the relation between individual contest expenditures and number of contestants using a Tobit specification and including controls for a time trend and gender. ${ }^{7}$ We report in Table 3 results based on all rounds of data, as well as from restricting the sample to the second half of the experiment, and perform the analysis separately for the small and large prize treatments. We cluster at the level of independent group in order to control for intra-group correlations.

As we saw in Fig. 1, contest investment decreases over time. The significant time trends in the regressions based on all rounds of data reflect this. Notably though, there are no significant time trends within the second half of the data. Consistent with equilibrium predictions, more entry leads to lower investment (although the effect is not significant at conventional levels in the second half of the small prize treatment, where the $p$ value is 0.147 ). The regression also indicates that women invest considerably more aggressively than men in the small prize treatment, a point we will return to later.

\subsubsection{Overdissipation}

The contest literature has long been concerned with the idea of overdissipation of rents - the possibility that the total investment in securing the prize ends up exceeding the value of the prize. While according to standard equilibrium analysis overdissipation

\footnotetext{
${ }^{6}$ From Sect. 3.2, note that with $N=6$ maximization of earnings differences results in equilibrium expenditures that are $20 \%$ higher for any given number of contestants than our equilibrium benchmark. Thus, this model cannot account for the mixed pattern of deviations from our benchmark. For example, the model cannot account for the scale of over-investment in Small Prize (2), which is far larger than can be accounted for by the relative earnings model, or in Large Prize (4) which is much smaller than would emerge from the relative earnings model.

7 Recall, investments are constrained to be between 0 and 100. Censoring is particularly important in the large prize treatment where about $10 \%$ of observations lie on the upper boundary of the choice set.
} 
Fig. 2 Overdissipation over time

Fig. 3 Kernel density estimations of investment (Stata default Epanechnikov kernel density estimator used)
- Relative frequency of rent dissipation levels above $100 \%$ -
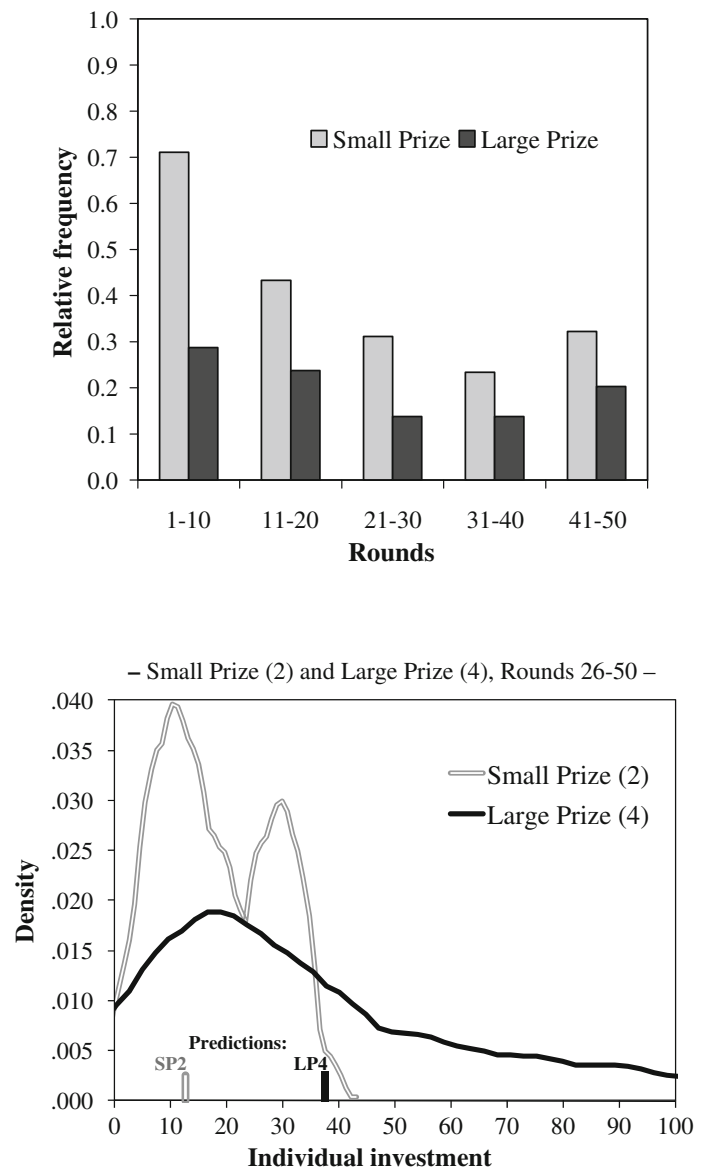

should never occur, the excessive investments we observe, particularly in the small prize treatment, suggest it as a possibility. As shown in Fig. 2, the phenomenon of overdissipation is not a rare occurrence in our treatments. Indeed, in the early rounds of the small prize treatment overdissipation appears to be the norm rather than the exception. Later, as subjects reduce their expenditures, the frequency of overdissipation diminishes but remains stubbornly high. Even in the large prize treatment, where average investments are often below the Nash prediction, overdissipation occurs almost $20 \%$ of the time over the last 10 rounds of the experiment.

Comparing Figs. 1 and 2 offers an apparent puzzle-how can investment in the large prize treatment fall mostly below the Nash prediction yet produce overdissipation almost $20 \%$ of the time? A key difference between the theory and actual behavior is the variability of investment decisions. To illustrate this, Fig. 3 presents a kernel density for investment in the large prize contest when $n=4$ based on the second-half data. For comparison the figure also shows a kernel density for the small prize contest 


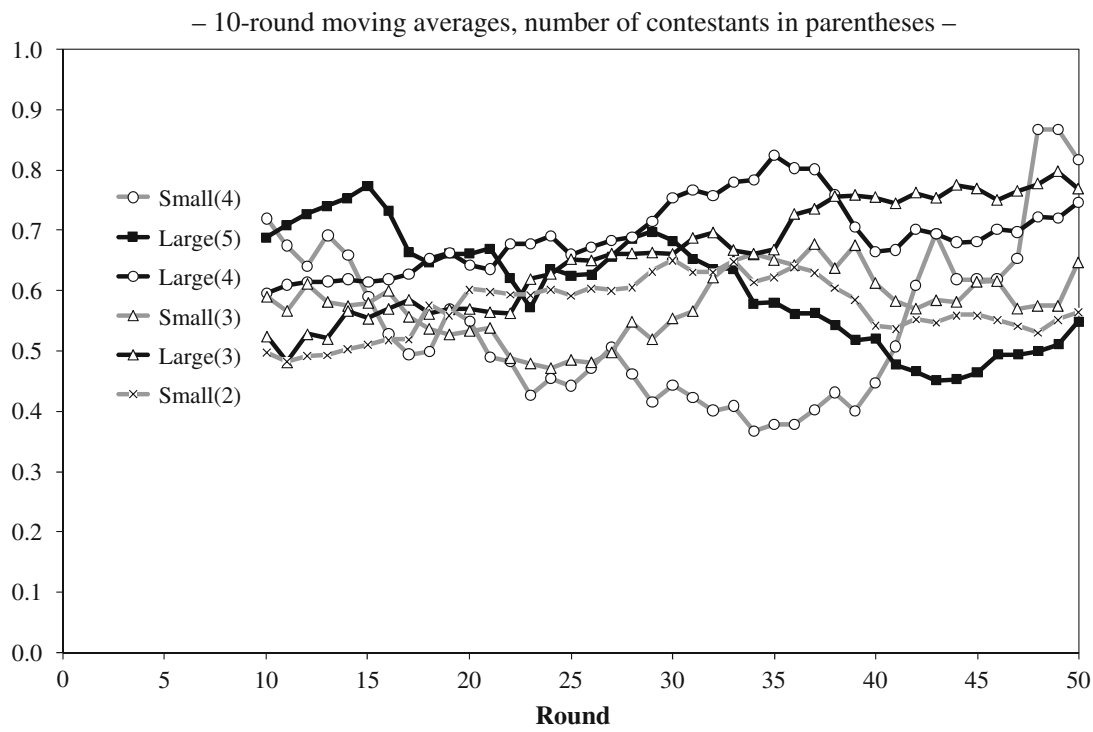

Fig. 4 Coefficient of variation over time

when $n=2$ (again based on second-half data). As the figure reveals, while the peak of the Large Prize (4) density occurs substantially below the Nash prediction, there is a long right tail which offers the possibility of severe overdissipation. In the small prize treatment, where overdissipation is common by any measure, there is a first peak around the Nash prediction and then a substantial second peak at a higher investment level. As a result, both the average investment and the frequency of overdissipation are high in this case.

The dispersion seen in Fig. 3 suggests that subjects are heterogeneous in their expenditure patterns. One might have thought that self-selection into the contest would minimize this heterogeneity if the players who choose to enter are all of a very similar "type". Thus, selection arguments would suggest a pattern of more homogeneous investments over time. Coefficient of variation offers a useful summary measure of the degree of dispersion in contest investments. Figure 4 plots this measure over the course of the experiment. As the figure shows, there is a high degree of investment dispersion, which persists throughout each session.

This variation is caused both by differences in bidding behavior across individuals and by within-individual variability in bidding behavior over time. For example, consider subjects in the large prize treatment who frequently compete in the contests with four players (i.e. their propensity to participate in Large Prize (4) is above the median). Calculating the average investment for each of these individuals in Large Prize (4) over all rounds, we find a coefficient of variation of 0.421 across these averages. Furthermore, calculating the coefficient of variation across rounds for each of these individuals yields an average of 0.527. The analogous figures for Small Prize (2) are 0.496 and 0.392 . 
Small Prize Treatment

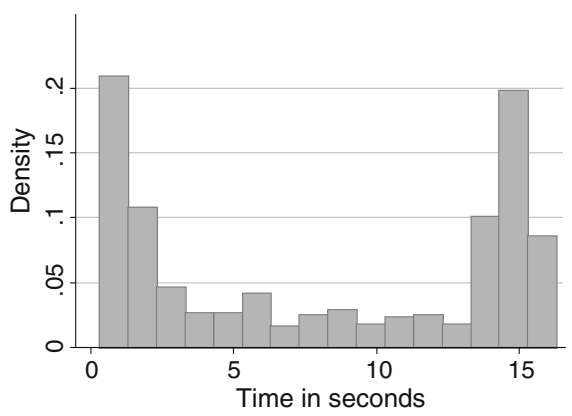

Fig. 5 Timing of entry decisions, rounds 26-50
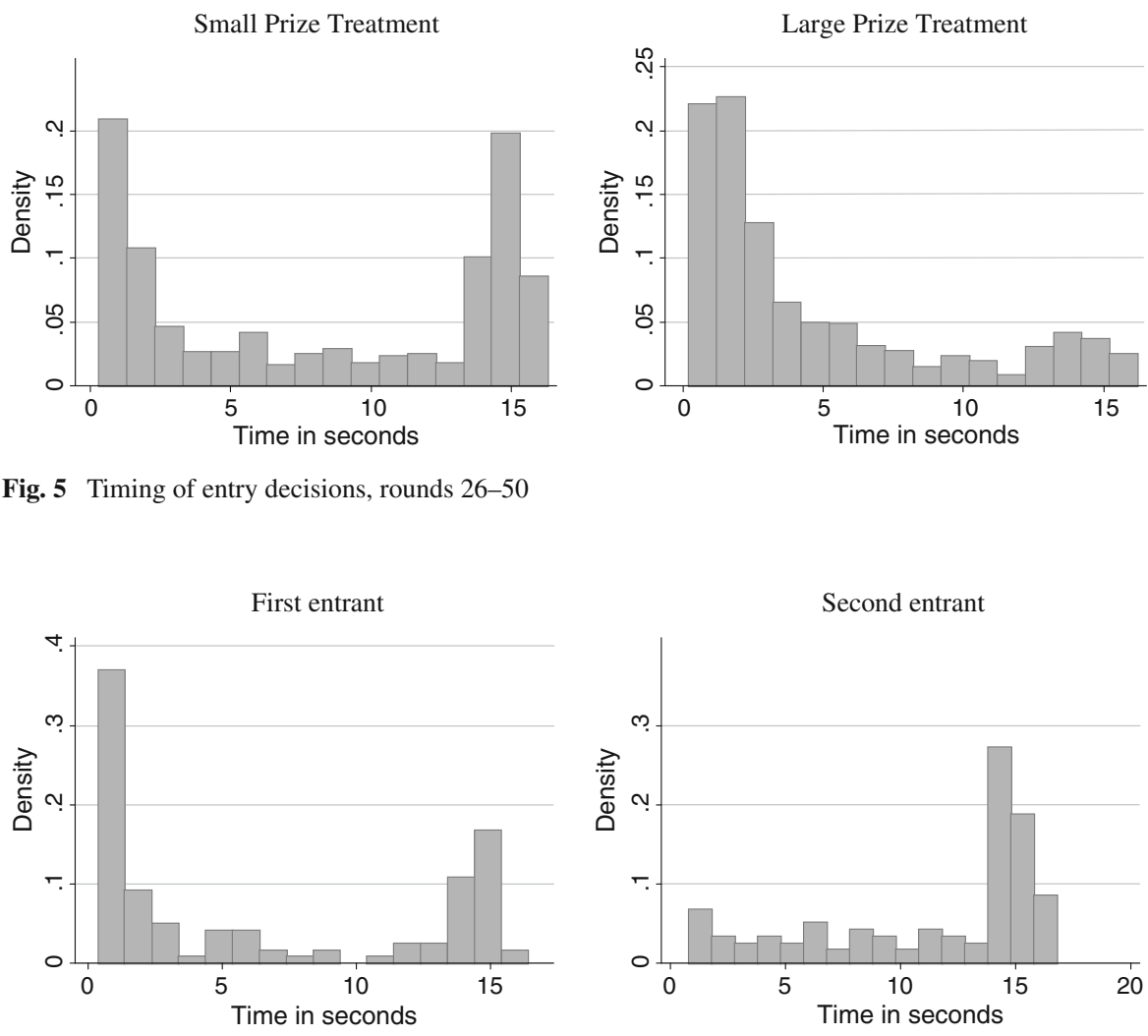

Fig. 6 Timing of entry decisions for $n=2$, small prize, rounds $26-50$

\subsection{Entry}

In our analysis of entry decisions we will first look at individual decisions about when to enter a contest and then examine the implications for earnings.

Theory predicts that entry will occur early as subjects seek to secure the superior rents from the contest relative to the outside option. Figure 5 displays the actual timing of subject decisions to enter the contest in the second half of the experiment. As the figure shows, timing in the large prize treatment is broadly consistent with the theory prediction-most entry occurs early. In the small prize treatment the timing pattern is very different: Contestants enter either very early or very late.

Figure 6 shows the timing decisions for small prize contests that end up with exactly two contestants. As the figure reveals, while the first contestant often enters early - usually in the first few seconds - the second contestant tends to use a "sniping" strategy_waiting until the last possible moment to enter.

One might expect that further entry would be less likely the more current entrants there are in a contest if the returns to entering a contest decline in the number of competitors. Anticipating this, subjects might rationally be less inclined to enter contests 
Fig. 7 Individuals' entry propensity as a function of the number of prior entrants

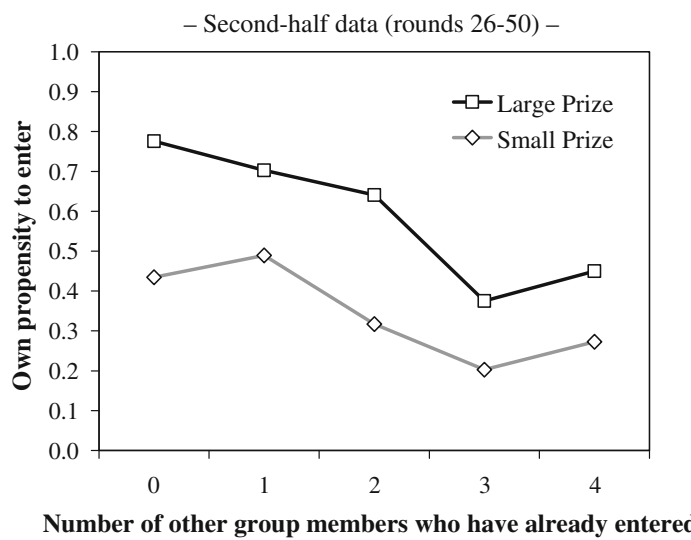

Table 4 Average payoff differences (in points) compared to the outside option

Empty cells ('-') indicate cases that were not observed in the experiment

\begin{tabular}{llllll}
\hline \multirow{2}{*}{ Entrants } & \multicolumn{2}{l}{ Small prize } & & \multicolumn{2}{l}{ Large prize } \\
\cline { 2 - 3 } \cline { 5 - 6 } \cline { 5 - 6 } & First half & Second half & & First half & Second half \\
\hline 1 & +40.0 & +40.0 & - & +190.0 \\
2 & -9.5 & -2.7 & & +12.5 & +16.8 \\
3 & -14.8 & -7.1 & & +12.2 & +12.2 \\
4 & -19.4 & -9.4 & & -1.0 & +6.1 \\
5 & -29.2 & -16.0 & & -8.8 & +6.6 \\
6 & - & -16.7 & & -9.8 & - \\
\hline
\end{tabular}

with more crowded fields of competitors. To investigate this possibility, we examine a subject's entry propensity - the probability that he or she will ultimately enter the contest - as a function of the number of competitors already in the contest at the time of the decision to enter or exit. Figure 7 displays the results of this analysis. As one would expect, entry propensities are consistently higher when the prize is large. Moreover, entry propensities generally decline with the number of rivals. ${ }^{8}$

Presumably, an important determinant for whether an individual decides to enter is the expected return from doing so relative to the fixed outside option. Table 4 shows the average contest returns (relative to the outside option) as a function of the number of contestants.

For the small prize contest, over-investment drives the expected payoff below the outside option even when there are only two entrants. As more players enter, expected earnings further deteriorate. For the large prize contest, returns turn negative only after there are four entrants in the first half of the experiment. In the second half, thanks to under-investment in the contest, even five entrants can profitably compete.

\footnotetext{
${ }^{8}$ Curiously, both treatments exhibit a slight uptick in entry when there are four other entrants as compared to three other entrants, but this seems to be mainly an artifact of the small number of observations for the five entrants case.
} 


\begin{tabular}{|c|c|c|c|c|c|}
\hline \multirow{2}{*}{$\begin{array}{l}\text { Table } 5 \text { Distribution of number } \\
\text { of entrants }\end{array}$} & \multirow[t]{2}{*}{ Entrants } & \multicolumn{2}{|c|}{ Small prize $(\%)$} & \multicolumn{2}{|c|}{ Large prize (\%) } \\
\hline & & First half & Second half & First half & Second half \\
\hline & 0 & 0.4 & 0.0 & 0.0 & 0.0 \\
\hline & 1 & 6.7 & 4.9 & 0.0 & 0.4 \\
\hline & 2 & 34.2 & 52.4 & 8.4 & 2.7 \\
\hline & 3 & 39.1 & 35.6 & 32.4 & 39.1 \\
\hline \multirow{3}{*}{$\begin{array}{l}\text { The italicized entries correspond } \\
\text { to the relevant equilibrium } \\
\text { prediction }\end{array}$} & 4 & 17.3 & 5.8 & 35.6 & 29.3 \\
\hline & 5 & 2.2 & 0.9 & 11.6 & 16.0 \\
\hline & 6 & 0.0 & 0.4 & 0.9 & 0.0 \\
\hline
\end{tabular}

Table 5 presents aggregate entry decisions. While the Nash prediction is that two players enter the small prize contest, one might expect that, on average, fewer than this number will choose to enter owing to the negative returns to two-person competition shown in Table 4. In fact, however, we observe precisely the oppositeon average there are 2.7 entrants in the first half of the experiment (rounds 1-25) and 2.5 in the second half (rounds 26-50). This reduction is statistically significant according to a two-sided randomization test applied to independent groups ( $p$ value $=$ 0.008). However, excess entry compared to the Nash prediction is statistically significant in both halves of the experiment (two-sided randomization test applied to independent observations: $p$ value $=0.004$ for rounds $1-25$ and 0.012 for rounds 26-50).

For the large prize contest, the Nash prediction is four entrants. Owing to underinvestment in the contest, one might expect more entry than the Nash prediction. Again, we observe precisely the opposite-on average there are 3.6 entrants in the first half and 3.7 in the second half. These figures differ from the Nash prediction at the $6 \%$ (first half) and $12.5 \%$ (second half) significance levels and despite profit opportunities from entry, there is no significant change in the number of entrants in the first versus second half of the experiment ( $p$ value $=0.708$ ), again using two-sided randomization tests applied to independent groups.

Because investment levels and entry rates vary across rounds we might expect variations in contest earnings also. Figure 8 presents the difference between average contest earnings and the outside option across rounds.

By allowing free entry and exit from the contest, it should be the case that the contest earnings are approximately equal to the outside option, and therefore earnings should be the same in the large prize and small prize contests. Instead, earnings appear to be much higher in the large prize contest.

To model dynamics in earnings and differences across treatments we regress earnings on a time trend and a dummy for the large prize treatment. Since gender influenced investment behavior in the small prize treatment we also include controls for gender. Standard errors are adjusted for intra-group correlation by clustering on independent groups. The results based on data from all rounds and data from the second half of the experiment are presented in Table 6. 


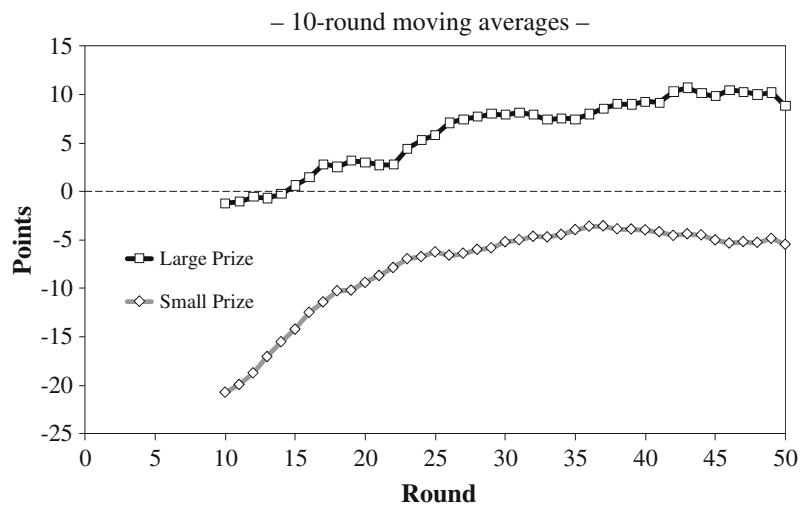

Fig. 8 Difference between contest earnings and outside option

Table 6 Determinants of individual contest earnings

Linear regression analysis with robust standard errors in parentheses

* Significant at $10 \%$

** significant at $5 \%$

*** significant at $1 \%$

\begin{tabular}{lll}
\hline & All rounds & Rounds 26-50 \\
\hline Constant & $95.439^{* * *}(4.192)$ & $110.875^{* * *}(3.865)$ \\
Large prize & $13.460^{* *}(5.274)$ & $12.260^{*}(6.729)$ \\
Round & $0.318^{* * *}(0.089)$ & $-0.010(0.084)$ \\
Female & $-6.044(3.529)$ & $-9.420^{* * *}(2.522)$ \\
Female * large prize & $2.223(4.853)$ & $-1.050(7.422)$ \\
Number of observations & 2581 & 1263 \\
$\mathrm{~F}(4,16)$ & $6.83^{* * *}$ & $5.37^{* * *}$ \\
\hline
\end{tabular}

As the table shows, while earnings increase over the course of the experiment, these gains are mostly confined to the first half of the session. Regardless of whether we focus on all rounds or just the second half of the data, there are significant earnings differences between the large and small prize contest. This is at odds with the theory, which predicts neutrality of earnings. It is evident from Fig. 8 that this is because contest earnings are lower than the outside option in the small prize contest, and higher than the outside option in the large prize contest. Women earn considerably less than men in both treatments, and the difference is significant in later rounds. We return to this gender effect later.

\subsubsection{Earnings disparities: individual characteristics and self-selection}

Could risk aversion help explain the discrepancies between contest earnings and the outside option? ${ }^{9}$ It is certainly possible to interpret the higher expected return from

\footnotetext{
9 One might also ask whether risk aversion might explain patterns of investment across contests with varying numbers of participants. A principal obstacle to interpreting our investment data from the viewpoint of risk preference theory is that at a general level different attitudes towards risk cannot be easily mapped into specific levels of rent-seeking activities. In particular, as shown by Konrad and Schlesinger (1997), risk aversion can either decrease or increase expenditures in rent-seeking contests compared to the risk-neutral case. Cornes and Hartley (2010), however, show that for standard preference specifications, risk aversion
} 
entering the large prize contest as a risk premium. However, to account for the results from the small prize treatment one would have to allow for the possibility of riskseeking behavior. By opting out of the contest, subjects could secure 110 points while avoiding the risk of the contest. Consider the behavior of "regular" contest participants who we define as individuals with an above-median entry rate in the small or large prize treatment. Based on the second-half data from the small prize contests, $85 \%$ of the regular contestants earn less in the contest than they would outside. ${ }^{10}$ Viewed through the lens of expected utility theory, this indicates risk-seeking preferences: these subjects, after having had ample opportunity to learn about the game and the strategic behavior of the other players, decide to enter frequently and to make investments such that their expected earnings fall below the payoff from the safe outside option. In contrast, the corresponding figure in the large prize treatment is only $35 \%$. That is, in this treatment most regular contestants expect to earn more than the outside option pays.

One interpretation of this pattern is a self-selection effect, where the most riskaverse subjects abstain from entering and the active contestants tend to be individuals with the highest inclination to take risks. Because the large prize attracts more entry than the small prize, one would then expect a higher concentration of risk seekers in the small prize contests. While the risk-seeking contestants over-invest in the small prize contest compared to the risk-neutral benchmark, they interact strategically with riskaverse players in the large prize contests, which ultimately produces under-investment compared to the risk-neutral benchmark.

If such self-selection is the explanation for the observed entry and investment decisions, we should observe that some subjects (the relative risk seekers) always enter the contests while others (the most risk-averse subjects) always stay out. To quantify the actual degree of sorting, we calculate for each of our groups a modified Gini coefficient of individual entry rates, in which we ask to what extent the six subjects in each group individually contribute to the "average number of entrants" figure we obtained at the aggregate level. With perfect sorting (it is always the same individuals who enter) our measure of the degree of sorting would deliver a value of 1 , while under complete absence of sorting (all individuals enter at the same rate) it would produce a value of zero. ${ }^{11}$ In the small prize treatment the average degree of sorting in the second half is 0.634 , and in the large prize treatment it is 0.719 . Thus, although the observed degree of sorting is closer to one than to zero, the self-selection of particular individuals for entry is certainly not as pronounced as one might expect under our hypothesized explanation.

\footnotetext{
Footnote 9 coninued

decreases contest expenditures. The theoretical analysis becomes even more intricate if some players are assumed to be risk-loving and/or players have incomplete information about each others' risk preferences.

10 To determine contest earnings we compute contestants' expected earnings before the lottery is resolved.

11 We use the conventional procedure for calculating the Gini coefficient except that we account for the fact that the benchmark of the most unequal pattern cannot be one where a single individual is responsible for all the entry. Thus, if the average number of entrants in a group is, say, 2.4 we define the most uneven pattern as two individuals with an entry rate of 1 , one individual with an entry rate of 0.4 and three individuals with an entry rate of zero. The benchmark of the most even pattern in this example is six individuals with an entry rate of 0.4 each.
} 
Another comparison between treatments is more damaging to the self-selection hypothesis. We frequently see three entrants in both the small prize and large prize treatment and, assuming that the distribution of risk attitudes in the two treatments is the same and that the self-selection forces also work in the same way, a comparison of these controls for differences in individual characteristics. Yet, we find that in the small prize three-player contest subjects over-invest and earn less than the outside option, whereas subjects in the large prize three-player contest under-invest and earn more. A two-sided two-sample randomization test applied at the group level shows the differences in earnings to be significant at the $1 \%$ level. ${ }^{12}$

Similar arguments can be made regarding self-selection based on other individual characteristics. For example, suppose individuals get utility from the event of winning the contest or from participating in the contest per se. This time the explanation appears more plausible for the small prize treatment where such a contest premium might explain the gap in expected earnings between entering and not entering. Explaining the reversed gap we observe in the large prize treatment is more problematic. Again, one might attempt to explain both by allowing for heterogeneity across individuals. Then, those who experience the strongest contest premium enter first and are willing to tolerate lower expected earnings than from the outside option, driving the main findings in the small prize treatment. In the large prize treatment with more entrants the marginal entrant has a negative contest premium and the interaction between these players with different individual characteristics leads to under-investment relative to the standard prediction. However, as before, this explanation does not survive a comparison of small prize and large prize contests controlling for the number of participants.

Our findings on under- and over-investment in rent-seeking are consistent with the broad picture from previous experiments with exogenous numbers of players, where most designs resulted in over-investment but some designs where prizes exceeded endowments resulted in under-investment relative to standard predictions (see Table 1). Thus, some of the observed discrepancies in investments across treatments could partially be explained by different relative endowments. ${ }^{13}$ In terms of entry decisions there is an interesting difference between our results and those from some experimental market entry games such as Kahneman (1988) study, where equilibrium organizes the data remarkably well. This seems to suggest that the forces of selection work considerably less well when the payoffs as a function of the number of entrants are endogenously determined as opposed to exogenously specified. However, we also note that our results are consistent with a number of experimental studies that report tendencies toward excess entry when theory predicts few entrants and under-entry when theory predicts many entrants. ${ }^{14}$

\footnotetext{
12 Further evidence against this hypothesis is provided in Morgan et al. (2010) who allow subjects to choose between entering a large or small prize contest. Risk seekers should be attracted to the riskier large prize contest; thus leading it to have a lower return. In fact, precisely the opposite result is obtained.

13 Sheremeta (2010) makes a similar point and finds evidence for this in two of his treatment variations.

14 See Camerer (2003) review in the context of market entry games and the results of Morgan et al. (2009) in the context of a route choice problem.
} 


\subsubsection{Boundedly rational entry decisions: quantal response equilibrium}

Excess entry in the small prize contest and insufficient entry in the large prize contest may reflect boundedly rational decision-making as captured by a quantal response equilibrium model. In this section our goal is to estimate "rationality" parameters for each treatment using the standard logit quantal response specification and assuming symmetry.

To implement this approach, there are two key obstacles we need to overcome. First, once entry occurs, the contest does not produce the expected payoffs that are predicted under the symmetric equilibrium; thus, determining the payoff to apply when $n$ subjects enter the contest requires some judgment. Second, entry decisions are made in continuous time where subjects are aware of the number of entrants already in the contest. Thus, a standard model of simultaneous entry decisions is not appropriate.

To model the game, we assume that contest stage expected payoffs when $n$ players enter equal the average payoffs during the second half of each experimental session. ${ }^{15}$ Second, we assume an exogenous random sequential ordering of entry decisions. Our theory section outlined a model where such an assumption is appropriate to describe equilibrium behavior.

We study symmetric subgame perfect quantal response equilibrium, which allows us to exploit backward induction to simplify the analysis. To see how this works, consider the final subject with the opportunity to enter. Define $\pi(n)$ to be the expected payoff from entering given that $n$ subjects enter in total. Define $\pi_{0}$ to be the payoff from staying out of the contest. Then the probability of entry for the last player given that $n-1$ players have already entered is

$$
p(n)=\frac{\exp [\lambda \pi(n)]}{\exp [\lambda \pi(n)]+\exp \left[\lambda \pi_{0}\right]}
$$

where $\lambda$ is the rationality parameter. Having identified these entry probabilities, we can then proceed recursively to determine the entry probabilities for the penultimate player, and so on. A subgame perfect QRE is a fixed point of this system.

It remains to compute the rationality parameter, $\lambda$. To do this, we compare the predicted distribution of entry decisions with the empirical distribution under a given treatment. We then compute the $\chi^{2}$ statistic for these distributions under a Pearson Chi-Square test and numerically estimate the value of $\lambda$ that minimizes this statistic. ${ }^{16}$ We obtain values of 0.063 and 0.064 for $\lambda$ under the small and large prize treatments, respectively. The test statistics associated with these optimized values are 0.269 and 0.162 , respectively, and we cannot reject the null hypothesis that empirical frequencies differ from the data generating process specified by the QRE.

While the QRE model can rationalize entry patterns in the data, it requires parameter values that attribute considerable randomness to decision making. For instance,

\footnotetext{
15 For the large prize treatment, there were no observations where all six players entered the game. For this case we use expected payoffs under symmetric risk-neutral Nash equilibrium instead.

16 Detailed calculations and accompanying Mathematica code are available upon request.
} 
Table 7 Gender difference in contest performance outcomes: average point earnings by treatment and gender

\begin{tabular}{lll}
\hline & Rounds 1-25 & Rounds 26-50 \\
\hline Small prize & & \\
Female & 94.5 & 101.6 \\
Male & 98.2 & 109.7 \\
Large prize & & \\
Female & 113.1 & 112.1 \\
Male & 111.5 & 123.2 \\
\hline
\end{tabular}

under the estimated value of $\lambda$, a subject choosing between payoffs of 100 and 110 is predicted to select 110 no more than one-third of the time. This seems unlikely to hold were subjects directly presented with these choices. Furthermore, this low degree of rationality implies that that choices in the contest itself would vary little with the size of the prize or the number of contestants, neither of which is true in the data.

\subsection{Gender}

Recently, there has been considerable interest in how performance under competition differs by gender and, in turn, how this affects gender distribution in competitive positions. Niederle and Vesterlund (2007) report results of laboratory experiments where subjects performed a number addition task. Despite observing no gender differences in terms of skill at doing the task, when a competitive payment system was implemented, women opted out of the competition at vastly greater rates than men. Similar results are reported in Cason et al. (2010). Gneezy et al. (2003) report results of laboratory experiments for a maze-solving task where entry was not endogenous. They find that increases in the competitiveness of tournament incentives lead to gap in the performance of men and women. In particular, men outperform women at the task when compensation is based on a tournament structure.

Like these papers, our experiments allow subjects to endogenously choose between a competitive compensation structure (the contest) and a fixed outside option. While our contest does not require skill at a specific intellective task (like maze-solving), performance in the contest does depend on the quality of their investment choice once in the contest. Thus, one might expect to find fewer women entering the contest and worse performance among those who entered.

How do women perform after selecting into the contest? Table 7 displays average point earnings of men and women choosing to participate in the contest. In the first 25 rounds of the experiment, we find little evidence of gender differences. However, in the last 25 rounds, a gender difference does emerge - the point earnings of women in the contest are lower than those of males. As noted earlier, this long-run difference in performance is significant in both treatments.

Since selection into the contest is endogenous, two different factors may account for the performance gap. Females may make worse investment decisions for a contest of a given size or they may enter contests having more entrants. Recall from Table 3 
Table 8 Gender difference in rivalry of contests entered: average number of entrants in a contest conditional on entering

Table 9 Gender difference in entry timing decisions: average time of decision to enter (in seconds)

\begin{tabular}{lll}
\hline & Rounds 1-25 & Rounds 26-50 \\
\hline Small prize & & 2.8 \\
Female & 3.1 & 2.6 \\
Male & 3.0 & \\
Large prize & & 4.0 \\
Female & 3.9 & 3.7 \\
Male & 3.8 & \\
\hline & & Rounds 26-50 \\
\hline & Rounds 1-25 & \\
\hline Small prize & & 8.3 \\
Female & 11.0 & 8.0 \\
Male & 10.0 & 5.3 \\
Large prize & & 4.2 \\
Female & 8.3 & \\
Male & 8.3 & \\
\hline
\end{tabular}

that in the large prize treatment there is no gender effect in investment conditional on the number of entrants. However, in the small prize treatments, females are considerably more aggressive in their rent-seeking expenditures than males. Since the average rent-seeking expenditures for this treatment are above Nash equilibrium levels, the even greater aggressiveness of females only serves to lower their average payoffs in the contest. ${ }^{17}$ Are women also more likely to enter contests with more rivals? Table 8 displays the average number of entrants in contests.

Overall, the contests women select into tend to have more contestants than the contests men select into. Using a standard t-test, the differences in the number of rivals in contests entered by men versus women are significant at the $10 \%$ level for both treatments in the first 25 rounds, and significant at the 5\% [1\%] level for the small [large] prize in the last 25 rounds.

How do women end up in contests with more rivals? One possibility is that women decide to enter the contest early and risk being in a contest with too many rivals. An alternative is that women wait to enter but are more optimistic than men about their prospects of winning a contest with a given number of rivals. Table 9 displays the timing of the average entry decision to enter sorted by gender.

As the table shows, we observe either little timing differences between men and women (first half large prize, second half small prize), or a tendency for men to enter sooner than women (first half small prize, second half large prize). The differences that occur are statistically significant (at the 5\% level for first half small prize and at the $1 \%$ level for second half large prize). Thus, it seems that the decision of females to enter

\footnotetext{
17 This result is in line with a number of other studies in which women are reported to bid more aggressively than men, e.g. Chen et al. (2005), Ham and Kagel (2006), Casari et al. (2007) and Charness and Levin (2009). We did not find any session effects that would suggest that women behave differently in sessions with relatively many or relatively few male participants in the room.
} 
Table 10 Gender composition in contests: fraction of females in a given treatment-choice

\begin{tabular}{lll}
\hline & Rounds 1-25 (\%) & Rounds 26-50 (\%) \\
\hline Small prize & & \\
$\quad$ Outside option & 55.2 & 55.7 \\
Contest & 56.0 & 55.3 \\
Large prize & & \\
$\quad$ Outside option & 32.2 & 36.6 \\
$\quad$ Contest & 41.0 & 38.3 \\
\hline
\end{tabular}

more crowded contests is not a product of their moving first and being unpleasantly surprised at the number of rivals.

Do women anticipate these performance differences and therefore eschew the contest at higher rates than their male counterparts? The answer is no. Table 10 displays the gender composition for the outside option and the contest. As the table shows, there is no evidence of a selection effect leading women not to participate in the contest. If anything, we observe the reverse - in the first 25 rounds of the large prize treatment, women are statistically significantly more likely to enter the contest at the $5 \%$ level.

To sum up, the performance gap is attributable to women entering more rivalrous contests and then bidding more aggressively than their male counterparts. These performance differences are apparently not anticipated correctly by women in our study, since they choose to enter the contest at the same rate as men. The latter result is especially surprising in light of the findings that women tend to be more risk averse than men (for example see Dohmen et al. 2005).

\section{Conclusions}

It is often suggested that departures from equilibrium observed in laboratory experiments are likely to be "cured" in practice through the discipline of the market. A common example is someone with intransitive preferences. Even if such a person existed, it is argued, he or she would have little bearing on the market since, thanks to being vulnerable to exploitation in the market, such an individual would have either exited or gone bankrupt. In this paper, we examine how anomalous contest behavior changes when subject to market discipline in the form of endogenous entry.

The authors had differing opinions on the applicability of this conventional wisdom to our setting. Some of us thought that by allowing subjects to endogenously choose whether or not to enter the contest, the "right" people would enter and equilibrium would be restored. Others thought that even if this might not be the case, our frictionless environment, the large number of iterations, and the clarity of the outside option would at least result in a situation where the expected payoffs from the inside option were approximately equal to those of the outside option. We all thought arbitrage opportunities would diminish with experience.

Our results, however, diverged greatly from our priors. While the dynamics of entry were consistent with market forces in the small prize contest, even at the end of the experiment subjects were earning less than their fixed outside option by participating 
in the contest. For the large prize contest, there was surprisingly little entry given the profit opportunities available. While initially payoffs were approximately equal across the two options, by the end of the experiment payoffs had drifted apart with the contest producing about $10 \%$ higher returns than the outside option. Although the simple comparative statics of the equilibrium predictions were borne out in the data, the level predictions were not. In the small prize contest, there was persistently too much entry and investment relative to equilibrium predictions. In the large prize contest, these results were reversed.

So what conclusions can we draw? First, the main power of the market is to affect the identity of the marginal individual opting in. In many markets, the marginal individual effectively sets the price in the market. In contest settings, however, the power of the marginal individual is more limited. Rent-seeking expenditures by inframarginal players can strongly affect the cost-benefit calculus of the marginal player thus blunting the force of the market at restoring equilibrium predictions.

The failure of the market to impose the "no arbitrage principle" is, in our view, more troubling. It suggests that, even in a simple setting like a contest, investment opportunities can persist unnoticed for a very long time. Presumably this is due to the complexity of determining the expected returns to entering the contest. Still, compared to most real world investment opportunities, the determination of contest returns given repeated exposure to the environment seems remarkably simple. Perhaps subjects take a satisficing approach to the entry decision: Once the payoffs from the inside and outside options were "close enough," there seemed little pressure to erase the remaining gains. It remains for future work to examine more systematically when being subjected to market pressures drives behavior toward equilibrium predictions and when it does not.

\section{Appendix: Instructions}

Welcome! You are about to take part in an experiment in the economics of decision making. You will be paid in private and in cash at the end of the experiment. The amount you earn will depend on your decisions, so please follow the instructions carefully.

It is important that you do not talk to any of the other participants until the experiment is over. If you have a question at any time, raise your hand and someone will come to your desk to answer it.

The experiment will consist of fifty rounds. In each round you will be matched with the same five other participants, randomly selected from the people in this room. Together, the six of you form a group. Note that you will not learn who the other members of your group are, neither during nor after today's session.

Each round is identical. At the beginning of the round you will be given an initial point balance of 100 points. You will then have up to $15 \mathrm{~s}$ to decide between option A and option B. If, at the end of that time, you have not made a choice, then the computer will make a choice for you by selecting randomly between the two options. During the $15 \mathrm{~s}$, your computer screen will keep you informed of how many group members have chosen each of the options so far, as well as the time remaining for you to make 
a choice. At the end of the $15 \mathrm{~s}$ the computer will display your choice and the number of group members choosing each option. Your final point earnings for the round will depend on your choice and the choices of other group members as described below.

At the end of the experiment one of the fifty rounds will be selected at random. Your earnings from the experiment will depend on your final point earnings in this randomly selected round. The final point earnings will be converted into cash at a rate of $10 \mathrm{p}$ per point.

\section{Option A}

If you select option A, 10 points will be added to your point balance. Your final point earnings for the round will be 110 points.

\section{Option B}

[Small Prize: If you select option B you will have a chance to win a prize of 50 points. First, if you are the only group member to select option B, you will automatically win the prize, and 50 points will be added to your initial point balance. Your final point earnings for the round will be 150 points.]

[Large Prize: If you select option B you will have a chance to win a prize of 200 points.

First, if you are the only group member to select option B, you will automatically win the prize, and 200 points will be added to your initial point balance. Your final point earnings for the round will be 300 points.]

Second, if more than one group member selects option B there will be a contest among these group members to determine who wins the prize. In this contest the players first decide how many "contest tokens" to buy. Each contest token you buy reduces your point balance by 1 point. You can purchase up to 100 of these tokens. Everybody will be making this decision at the same time, so you will not know how many contest tokens the other players have bought when you make your choice. You will have $30 \mathrm{~s}$ to make a decision about how many contest tokens to buy. If you do not make a decision within this time limit the computer will make a choice for you by selecting zero tokens.

If nobody buys any tokens, nobody wins the prize. Otherwise, your chances of winning the prize will depend on how many contest tokens you buy and how many contest tokens the other players buy. This works as follows:

A computerized lottery wheel will be divided into shares with different colors. One share belongs to you and the other shares belong to each of the other players (a different color for each player). The size of your share on the lottery wheel is an exact representation of the number of contest tokens you bought relative to all contest tokens purchased. For instance, if you own just as many contest tokens as all the other players put together, your share will make up 50\% of the lottery wheel. In another example, suppose that there are four players (including you) and that each of you owns the same number of contest tokens: in that case your share will make up $25 \%$ of the lottery wheel. 
Once the shares of the lottery wheel have been determined, the wheel will start to rotate and after a short while it will stop at random. Just above the lottery wheel there is an indicator at the 12 o'clock position. The indicator will point at one of the shares, and the player owning that share will win the prize. Thus, your chances of winning the prize increase with the number of contest tokens you buy. Conversely, the more contest tokens the other players buy, the lower your chances of receiving the prize.

[Small Prize: If you win the prize 50 points will be added to your point balance. Your final point earnings for the round will be $(100$ - the number of contest tokens you bought +50 ) points.]

[Large Prize: If you win the prize 200 points will be added to your point balance. Your final point earnings for the round will be (100- the number of contest tokens you bought +200 ) points.]

If another player wins the prize zero points will be added to your point balance. Your final point earnings for the round will be $(100$ - the number of contest tokens you bought) points.

Now, please look at your computer screen and begin making your decisions. If you have a question at any time please raise your hand and a monitor will come to your desk to answer it.

Open Access This article is distributed under the terms of the Creative Commons Attribution Noncommercial License which permits any noncommercial use, distribution, and reproduction in any medium, provided the original author(s) and source are credited.

\section{References}

Abbink, K., Brandts, J., Herrmann, B., Orzen, H.: Inter-group conflict and intra-group punishment in an experimental contest game. Am Econ Rev 100, 420-447 (2010)

Anderson, L.R., Stafford, S.L.: An experimental analysis of rent-seeking under varying competitive conditions. Public Choice 115, 199-216 (2003)

Braga, J., Humphrey, S., Starmer, C.: Market experience eliminates some anomalies-and creates new ones. Eur Econ Rev 53, 401-416 (2009)

Camerer, C.: Behavioral game theory: experiments in strategic interaction. Princeton: Princeton University Press (2003)

Casari, M., Ham, J.C., Kagel, J.H.: Selection bias, demographic effects, and ability effects in common value auction experiments. Am Econ Rev 97, 1278-1304 (2007)

Cason, T.N., Masters, W.A., Sheremeta, R.M.: Entry into winner-take-all and proportional-prize contests: an experimental study. J Public Econ (2010, forthcoming)

Charness, G., Levin, D.: The origin of the winner's curse: a laboratory study. Am Econ J Microecon 1, 207-236 (2009)

Chen, Y., Katuscak, P., Ozdenoren, E.: Why can't a woman bid more like a man? University of Michigan Working Paper (2005)

Corcoran, W.: Long-run equilibrium and total expenditures on rent-seeking. Public Choice 43, 89-94 (1984)

Corcoran, W., Karels, G.: Rent-seeking behavior in the long-run. Public Choice 46, 227-246 (1985)

Cornes, R., Hartley, R.: Risk aversion in symmetric and asymmetric contests. Econ Theory (2010). doi: 10.1007/s00199-009-0490-9

Cox, J., Grether, D.: The preference reversal phenomenon: response mode, markets and incentives. Econ Theory 7, 381-405 (1996)

Davis, D.D., Reilly, R.J.: Do too many cooks always spoil the stew? An experimental analysis of rent-seeking and the role of a strategic buyer. Public Choice 95, 89-115 (1998) 
Dohmen, T., Falk, A., Huffman, D., Sunde, U., Schupp, J., Wagner, G.: Individual risk attitudes: new evidence from a large, representative, experimentally-validated survey. IZA Discussion Paper 1730 (2005)

Fonseca, M.A.: An experimental investigation of asymmetric contests. Int J Ind Organ 27, 582-591 (2009)

Fullerton, R.L., McAfee, R.P.: Auctioning entry into tournaments. J Polit Econ 107, 573-605 (1999)

Gneezy, U., Niederle, M., Rustichini, A.: Performance in competitive environments: gender differences. Q J Econ 118, 1049-1074 (2003)

Ham, J., Kagel, J.: Gender effects in private value auctions. Econ Lett 92, 375-382 (2006)

Hehenkamp, B., Leininger, W., Possajennikov, A.: Evolutionary equilibrium in tullock contests: spite and overdissipation. Eur J Polit Econ 20, 1045-1057 (2004)

Herrmann, B., Orzen, H.: The appearance of homo rivalis: social preferences and the nature of rent-seeking. CeDEx Discussion Paper 2008-10, University of Nottingham (2008)

Kahneman, D.: Experimental economics: a psychological perspective. In: Tietz, R., Albers, W., Selten, R. (eds.) Bounded Rational Behavior in Experimental Games and Markets, Berlin: Springer (1988)

Kong, X.: Loss aversion and rent-seeking: an experimental study. CeDEx Discussion Paper 2008-13, University of Nottingham (2008)

Konrad, K.A.: Strategy in contests: an introduction. WZB-Markets and Politics Working Paper No. SP II 2007-01 (2007)

Konrad, K.A., Schlesinger, H.: Risk aversion in rent-seeking and rent augmenting games. Econ J 107, 1671-1683 (1997)

Mathews, T., Namoro, S.: Participation incentives in rank-order tournaments with endogenous entry. J Econ 95, 1-23 (2008)

Millner, E.L., Pratt, M.D.: An experimental investigation of efficient rent-seeking. Public Choice 62, 139-151 (1989)

Millner, E.L., Pratt, M.D.: Risk aversion and rent-seeking: an extension and some experimental evidence. Public Choice 69, 81-92 (1991)

Morgan, J., Steiglitz, K., Reis, G.: The spite motive and equilibrium behavior in auctions. Contributions to Economic Analysis and Policy 2:1, Article 5 (2003)

Morgan, J., Orzen, H., Sefton, M.: Network architecture and traffic flows. Games Econ Behav 66, 348372 (2009)

Morgan, J., Orzen, H., Sefton, M.: Does entry eliminate economic profit? An experimental study. University of California, Berkeley Working Paper (2010)

Niederle, M., Vesterlund, L.: Do women shy away from competition? Do men compete too much? Q J Econ 122, 1067-1101 (2007)

Nitzan, S.: Modeling rent seeking contests. Eur J Polit Econ 10, 41-60 (1994)

Potters, J., de Vries, C., van Winden, F.: An experimental examination of rational rent-seeking. Eur J Polit Econ 14, 783-800 (1998)

Schmidt, D., Shupp, R., Walker, J.: Resource allocation contests: experimental evidence. CAEPR Working Paper, No. 2006-004 (2006)

Schmitt, P., Shupp, R., Swope, K., Cadigan, J.: Multi-period rent-seeking contests with carryover: theory and experimental evidence. Econ Governance 5, 187-211 (2004)

Sheremeta, R.M.: Experimental comparison of multi-stage and one-stage contests. Games Econ Behav 68, 731-747 (2010)

Sheremeta, R.M.: Contest design: an experimental investigation. Econ Inquiry (2010). doi:10.1111/j. 1465-7295.2009.00274.x

Shogren, J.F., Baik, K.H.: Reexamining efficient rent-seeking in laboratory markets. Public Choice 69, 69-79 (1991)

Shupp, R.: Single versus multiple winner rent-seeking contests: an experimental investigation. Ball State University Working Paper (2004)

Skaperdas, S.: Contest success functions. Econ Theory 7, 283-290 (1996)

Tullock, G.: The welfare costs of tariffs, monopoly and theft. Western Econ J 5, 224-232 (1967)

Tullock, G: Efficient rent-seeking. In: Buchanan, J.M., Tollison, R.D., Tullock, G. (eds.) Toward a Theory of Rent-Seeking Society, pp. 97-112. College Station: Texas A\&M University Press (1980) 